\title{
The development of habituation in the rat*
}

\author{
PAUL M. BRONSTEIN $\dagger$, HOWARD NEIMAN, F. DMITRI WOLKOFF, and M. JOV LEVINE \\ Brooklyn College of the City University of New York, Brooklyn, New York 11210
}

\begin{abstract}
In each of two studies, rats of different ages were given one prolonged open-field trial. Animals of 21 days and older displayed within-session activity decrements, while 15-day-olds failed to habituate. The abrupt transition from a pattern. of nonhabituation to one of habituation to a novel environment parallels the development of forebrain cholinergic mechanisms during the third and fourth postnatal weeks. These experiments conform to the suggestion that the 2 -week-old rat is behaviorally similar to the hippocampectomized adult.
\end{abstract}

In none of the studies of the ontogeny of rats' open-field behaviors originating in this laboratory (Bronstein, 1972) has there been any clear difference in habituation rates among the various age groups. The level of locomotor activity (e.g., square crossing) has always appeared as a decreasing function of apparatus exposure on any given day. The greatest activity decrement appears between the first and second minutes of a 5-min trial; however, such declining rates of ambulation have appeared rather uniformly among animals varying in age from 30 to 175 days.

That younger rats habituate at a rate similar to that of the adults is an unexpected finding in the light of the many reports of very persistent play and exploratory behaviors among immature animals in a variety of settings (cf. Eibl-Eibesfeldt, 1970). Martinek and Lat (1968), for example, have shown that many behavior patterns of canines are slower to habituate in pups than in adults. And in an excellent review, Harper (1970) discusses some of the unique social and ecological pressures on young mammals that might have selected for persistently active and gregarious juveniles.

One suggestion to account for the relatively undifferentiated rates of open-field habituation in the rat during the second through fourth months of life is that the youngest Ss may already be old enough to show the pattern of habituation typical of adults. Campbell, Lytle, and Fibiger (1969) and Douglas (1972) have speculated that the rapid development of the rat's hippocampus during the third and fourth postnatal weeks represents the onset of a mechanism, the integrity of which is essential for behavioral adjustments (habituation, extinction) to biologically insignificant stimuli (Carlton, 1963, 1969).

The two studies presented here are tests of the hypothesis that 2-week-old rats display unusually persistent locomotor activity and are behaviorally much

\footnotetext{
*This research was supported by Grant 1442 from the Research Foundation of the City University of New York and by Grant MH22027-01 from the National Institute of Mental Health. We wish to thank Joseph Gavlick and David Small for their technical assistance during the preparation of this paper.

tRequests for reprints should be addressed to Paul $M$. Bronstein, Department of Psychology, Brooklyn College, Brooklyn, New York 11210.
}

like adults with bilateral hippocampal lesions in their failure to show an activity decrement with increased exposure to a new locale (Roberts, Dember, \& Brodwick, 1962). Also, the transition from nonhabituators to habituators should be found in the third week post partum, the period during which the rat's brain cholinergic system is rapidly maturing (Campbell et al, 1969).

\section{EXPERIMENT I}

\section{Method}

Subjects. The Ss were 24 albino rats, eight each at 15,21 , and approximately 100 days of age. All animals were of Sprague-Dawley descent and born in the Brooklyn College colony from stock acquired from Perfection Breeders, Douglassville, Pennsylvania. Approximately half of the Ss in each age group were male, and all animals were maintained on ad lib Purina lab chow and water in a colony illuminated from $8 \mathrm{a} . \mathrm{m}$. to 2 a.m. daily. The 100-day-olds (adults) had been weaned when 21 days old and housed two of the same sex to a cage thereafter; they were handled daily for an 8-day period when they were 25 days old and unhandled thereafter until the start of the present study. The two youngest groups, created by splitting each of two litters, were housed with their mothers in a plastic litter cage throughout the study. Each of the rats in the two youngest groups had its eyes open by Day 15 .

Apparatus. A clear Plexiglas open field, $60.96 \mathrm{~cm}$ high and wide and $59.69 \mathrm{~cm}$ deep, was used. The apparatus was placed within a sound-insulated outer shell $(91.44 \mathrm{~cm}$ high and measuring $73.66 \mathrm{~cm}$ on a side) that was fitted with a blower to mask external noises and open on one side, rendering the open field accessible to observation. Ss were placed in to the apparatus through a $12.07 \times 12.70 \mathrm{~cm}$ door in a corner of the front wall of the field. The tan Plexiglas floor of the open field was quartered by two $1 / 4 \mathrm{~cm}$ wide, perpendicular black lines intersecting at the floor's center, and a 1.12-W bulb centered on the ceiling of the open field illuminated the chamber. The upper portion of the front wall of the open field could be swung outward, thus facilitating the removal of the rats following an observation period.

Procedure. Each S was lifted from its home cage and carried to the apparatus, where its activity was observed for one 15 -min trial. After placing the $\mathrm{S}$ into the open field, the $\mathrm{E}$ manually operated a console of four pushbuttons used to record the number of squares crossed and duration of horizontal movement, as well as the frequency and duration of rearing and grooming behaviors. These dependent variables were registered on separate clocks and counters (located in another part of the laboratory) for each $5 \mathrm{~min}$ of a trial. 


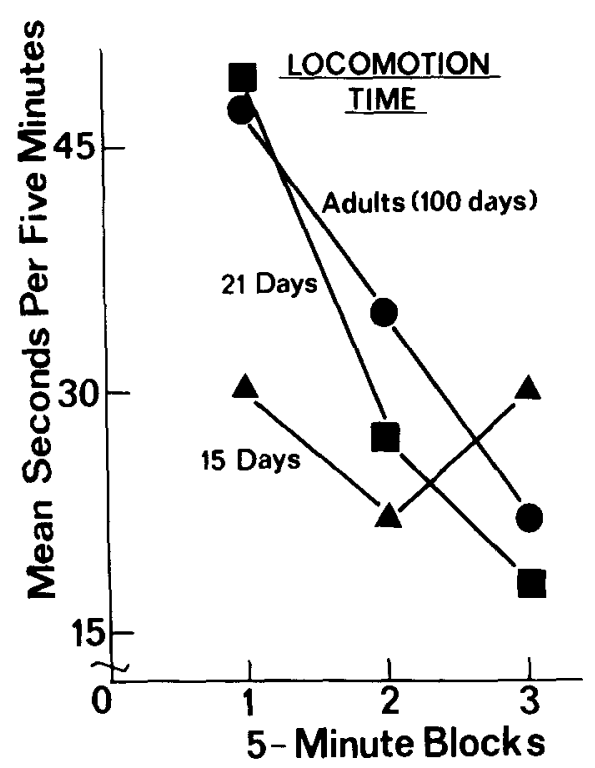

Fig. 1. Mean time spent locomoting as a function of age and intratrial minutes (Experiment I).

Latency to traverse the first square was also recorded. This was accomplished by manually starting a clock when the door to the field was closed behind an animal; this timer was automatically shut down when the first square cross was registered. Times of less than $1 / 2 \mathrm{sec}$ could be reliably recorded in this manner, providing greater sensitivity than the behavior of the Ss warranted. A square was considered traversed when a S's head and at least one forepaw extended over a black dividing line. Horizontal movement meant any quadrupedal locomotion, i.e., walking or running. Rearing or standing-up behavior occurred when an animal's forepaws were lifted concurrently in any context other than that for rubbing or scratching its body. These latter actions were considered grooming, a category also including any licking or biting of the body.

At the end of the trial, the $S$ was returned to its home cage, any excreta recorded, and the floor of the open field wiped clear with dilute acetic acid to mask any possible odor trails.

\section{Results}

Analyses of variance, supplemented by Newman-Keuls and two-tailed $t$ tests, were used to examine the changes in behavior of each group during repeated 5-min blocks within a trial (Winer, 1962).

Figure 1 depicts the effects of age and trial duration upon ambulation time. There was no significant effect of age per se $(F<1.00)$, but the intensity of ambulation did wane significantly as the trial proceeded $(p<.01)$, and the interaction of Age by Trial Blocks also proved significant $(p<.05)$. Newman-Keuls tests revealed the significant interaction to result from the activity decrements among the oldest two groups $(p<.01$ for each). The 15-day-olds showed no significant block to block reduction in their activity.

The square crossing and rearing frequency data mirrored quite closely the results on the ambulation time variable. On each measure there was an activity decrement within a trial ( $<<.01$ for both), as well as a significant Age by Blocks interaction $(p<.05)$, indicating that only the two oldest groups displayed this activity change. No significant habituation was noted in the 15-day-olds. Furthermore, a significant main effect of age was apparent within each variable $(p<.01$ for both), with post hoc tests showing that the adults both crossed more squares and engaged in rearing behavior more frequently than either of the younger groups $(t \geqslant 2.702, \mathrm{df}=14, \mathrm{p}<.02)$.

The main effect of age proved to be the only factor significantly influencing rearing duration and the frequency and duration of grooming behavior. On none of these variables was any significant habituation apparent. The youngest Ss displayed significantly more grooming $\left(\overline{\mathrm{X}}_{15}=8.63\right.$ bouts per trial) than either of the older groups (Newman-Keuls, $p<.01$ for both), while 21-day-olds groomed significantly longer than both adults and 15-day-olds (Newman-Keuls, $p<.05$ for both). The adults spent significantly more time rearing $\left(\overline{\mathrm{X}}_{\mathrm{adults}}=149.9 \mathrm{sec} /\right.$ trial $)$ than either of the two youngest groups (Newman-Keuls, $p<.05$ for both). Finally, the latency to the initial square crossing was not significantly influenced by the age variable.

In confirmation of the main hypotheses, the two oldest groups showed significant habituation of square crossing, rearing frequency, and the duration of open-field ambulation. Contrastingly, the 15-day-olds showed no significant within-trial decrements. However, in each of these analyses where an Age by Blocks interaction was in evidence, the three groups were undifferentiable statistically during the final $5-\mathrm{min}$ block. Therefore, the lack of significant habituation among the youngest Ss might represent a basement effect, i.e., the activity level of the 15-day-olds might have been too low at the start of the trial to be further diminished over time. This last possibility provided the main impetus for conducting the second study, employing longer open-field trials.

\section{EXPERIMENT II}

The Ss were 11 15-day-old and 11 21-day-old albino rats raised and housed in conditions identical to those of the two youngest groups in the first study. Five siblings with their eyes still unopened on Day 15 were run following eye opening when they were 16 days old. The two groups were constructed by randomly splitting each of three litters, with the stipulation that approximately half of the Ss in each age group were male.

Experiment II employed the same equipment and methodology as the first investigation, with the exception that the behavioral observations were made during a 30-min trial and, second, that the criterion for traversing a square was made more stringent. A S's head and each of three limbs had to cross a dividing line before a square was judged to have been traversed.

\section{Results}

The methods of data analysis were identical to those 
of Experiment I, with the results of the two proving highly compatible. As is demonstrated in Fig. 2, age did not exert a significant influence over locomotion time, while the Age by Blocks interaction and the main effect of intratrial blocks were significant $(p<.01$ for both). Newman-Keuls tests revealed that the 21-day-olds ambulated significantly longer during the first 5-min block than in the subsequent interval $(\mathrm{p}<.01)$. Also, the 15-day-olds exhibited significantly greater ambulation during the second block than in either Block 5 or 6 , respectively $(p<.05)$. Further post hoc comparisons revealed that the 21-day-olds were significantly more active than the younger animals during the initial 5-min block $(\mathrm{t}=4.596, \mathrm{df}=20$, $\mathrm{p}<.001$ ), while the 15 -day-olds were significantly more active than the 21-day-old Ss at trial's end $(t=2.724$, $\mathrm{df}=20, \mathrm{p}<.02$ ). Similarly, analysis of the square crossing data showed a pattern quite compatible with the ambulation time results. As seen in Fig. 3, the main effect of intratrial blocks and the Age by Blocks interaction were significant ( $p<.01$ for both), although the age variable exerted no significant effect upon square crossing $(\mathrm{F}<1.00)$. Post hoc comparisons revealed that the 21-day-olds crossed significantly more squares during the first 5-min block than in the second (Newman-Keuls, $\mathrm{p}<.01$ ), and their square crossing was significantly greater during the second than in any of the subsequent blocks (Newman-Keuls, $p<.05$ for all). The youngest animals showed no significant changes in activity during the trial.

The 21-day-old animals were crossing significantly more squares during the first $5 \mathrm{~min}$ than were the 15 -day-olds $(t=5.881, d f=20, p<.001)$, while at the end of the trial the 15-day-olds were significantly more active than their older littermates $(t=2.705$, $d f=20$,

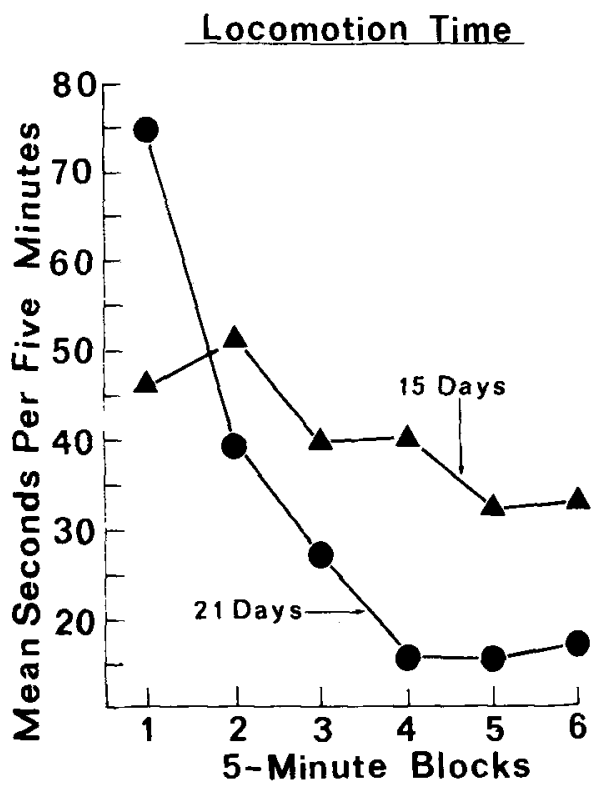

Fig. 2. Mean time spent locomoting as a function of age and intratrial minutes (Experiment II).

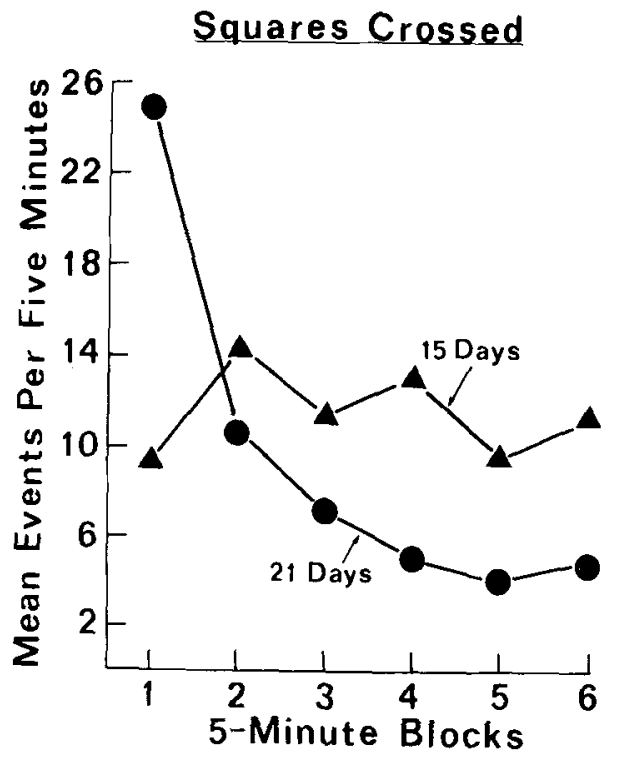

Fig. 3. Mean number of squares crossed as a function of age and intratrial minu tes (Experiment II).

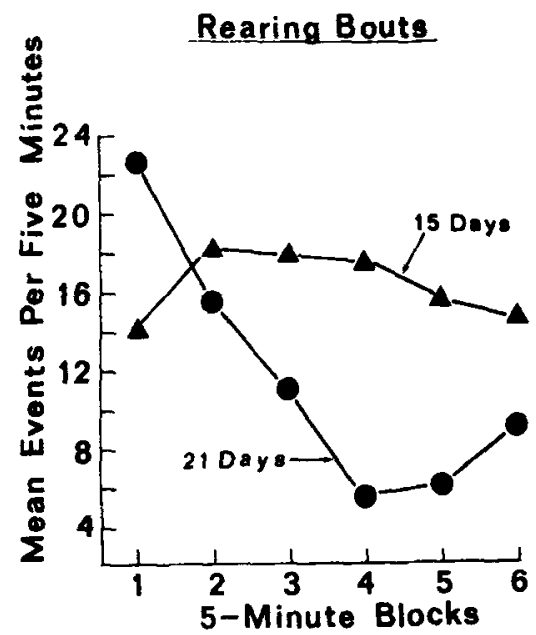

Fig. 4. Mean number of rearing bouts as a function of age and intratrial minu tes (Experiment II).

$\mathrm{p}<.02)$. Thus, the significant Age by Blocks interactions noted for the variables of square crossing and ambulation time are the result of the 15-day-olds' activity not decreasing significantly within a session. These results cannot be interpreted as a basement effect among the youngest rats.

Also, the rearing frequency of the animals paralleled the behavior on this measure in Experiment $I$, as well as being similar to the locomotor behaviors in both studies. As graphically represented in Fig. 4, the effect of age upon the number of standing-up actions proved negligible, while the main effect of blocks and the Age by Blocks interaction were significant $(p<.01$ for both). Newman-Keuls tests showed a significant intratrial decrement in rearing among the 21-day-olds ( $p<.01)$; among the 15-day-old rats there was no significant change in rearing behavior throughout the 
30-min session. The older Ss reared significantly more frequently than the 15-day-olds during Block 1 $(t=2.75, d f=20, p<.02)$, and during the fourth intratrial block the rearing decrement among the 21-day-olds was sufficient to cause these rats to be rearing significantly less frequently than the 15-day-olds $(\mathrm{t}=4.65, \mathrm{df}=20, \mathrm{p}<.001)$.

As in Experiment $I$, analyses of the open-field activities other than the two measures of locomotion and rearing frequency revealed patterns dissimilar to these three dependent variables. Grooming was influenced significantly by the age variable alone; the 21-day-olds engaged in this behavior more frequently $\left(\overline{\mathrm{X}}_{21}=36.54\right.$ bouts/trial $)$ and for a greater time than the younger $S s(p<.01$ for both measures). No significant intratrial decrement in grooming behaviors was noted. Also, each group spent an average of approximately $3 \mathrm{~min}$ of the $1 / 2-\mathrm{h}$ trial in rearing, and no intergroup difference was apparent $(F<1.00)$. Last, the 21-day-old Ss traversed their first square with a mean latency of $10.70 \mathrm{sec}$, significantly faster than the average of $82.79 \mathrm{sec}$ taken by the younger animals $(\mathrm{t}=3.28$, $\mathrm{df}=20, \mathrm{p}<.01$ ).

\section{DISCUSSION}

Both major hypotheses have been confirmed. First, 15-day-old rats failed to attenuate their open-field activities during apparatus exposures of as long as $1 / 2 \mathrm{~h}$. Second, large activity decrements were apparent among 21- and 100-day-olds after as little as $10 \mathrm{~min}$ in the open field. The present data very much conform to the theory that the 2-week-old rat, as with the hippocampectomized adult, is deficient in some central response-inhibition process mediating habituation. Also, there is no other theory of which we are aware that predicts this rapid change in behavior. Further, no habituation of grooming responses was noted at any age, and this finding is in agreement with the observations of Bolles (1960) and Tapp (1969).

From developmental investigations of T-maze alternation (Douglas, Peterson, \& Douglas, 1973) ${ }^{1}$, nose-poking behavior (Feigley, Parsons, Hamilton, \& Spear, 1972), reactions to drugs affecting central cholinergic pathways (Campbell et al, 1969), passive-avoidance acquisition (Riccio \& Schulenburg, 1969; Schulenburg, Riccio, \& Stikes, 1971), and now open-field adaptation, it becomes clear that 15-day-old rats are very different from conspecifics as little as 6 days older. Also, the behavior on each of these criterion tasks shows the younger Ss to differ in a manner that is completely consistent with their being considered identical to adults (e.g., 100-day-olds) with bilateral hippocampal lesions and, therefore, lacking a system of response inhibition, perhaps. The inference that the development of this limbic structure is largely responsible for this syndrome of behavioral ontogenesis seems worthy of further investigation, and the description of postnatal neurogenesis by Altman and his colleagues (e.g., Altman \& Das, 1965) further supports this contention.

In spite of this parsimonious view of a rat's development, constructed from behavioral and neurological parallels, some skepticism and alternative possibilities should be presented. First, the absence of any activity decrement among the 15-day-olds may be a manifestation of their endogenous levels of responding, while the significant decrements among older rats in both studies may indicate that their behavior is elicited or under the control of exogenous factors to which habituation is possible. It might, therefore, be inappropriate to use the term "habituation" for a variety of age groups without first being aware of the relevant stimuli, if any, to which the Ss are responding. This question of stimulus control, as far as we are aware, has not yet been addressed by any investigators working in this area.

Second, it is not at all clear whether the present studies should be interpreted as representing the development of a central inhibitory process or, conversely, the onset of heightened susceptibility to peripheral fatigue after the third week of a rat's postnatal ontogeny. Unfortunately, these two explanations are confounded in the current studies, nor were Feigley et al (1972) able to dispel this fatigue-based interpretation convincingly. In these latter experiments, light-contingent nose poking was recorded and, just as in the current work, 15-day-old rats were unique in their maintenance of high levels of responding without the activity decrements typical of older animals. Similarly, most of the other age-related effects could be explained in a post hoc fashion by assuming that 15-day-olds are less susceptible to fatigue than older rats and, therefore, ambulate more persistently. Only the data on spontaneous alternation, a behavior that involves a directional response in addition to not being explained too well on the basis of response-fatigue theories (cf. Dember, 1961), cannot be accounted for in this manner.

Finally, some attention must be paid to the possible influence of environmental changes and restrictions, especially mother-pup and sibling interactions, in contributing to the persistence of locomotor activities in the 15-day-old rat. Specifically, it is during the third week postpartum that the young rat begins to initiate most of the contacts made with the maternal female, while the dam continues to provide her young with a large fraction of their daily nutriment (Rosenblatt \& Lehrman, 1963). Thus, quadrupedal locomotion that occurs in the rat from about Day 13 (Bolles \& Woods, 1964; Blanck, Hard, \& Larsson, 1967) may be reinforced initially by the lactating female, either through physical contact with or nursing of the pups. Within about 1 week after the pups are locomoting, however, they may be sufficiently independent of the dam nutritionally so that, with food strewn abundantly about the cages (as in the present procedure), the pups may no longer 
experience long bouts of locomotion followed by feeding. Experiments by Galef and Clark (1972) and Krecek (1971) suggest that in the absence of human intervention rat pups will be at least partially weaned by Day 21 ; therefore, the ontogeny of ambulation and of independent eating in the rat is such that these two behaviors may interact to produce the persistent locomotion of 15-day-olds.

In explaining the variety of behavioral changes occurring between Days 15 and 21 in the rat pup, it seems highly appropriate to consider experiential alternatives to the more prevalent physiological hypotheses of Douglas (1972) and others.

To conclude, then, we have gathered some information that extends previously existing ideas about the behavioral ontogeny of the rat. However, these and other data that have been used to support a central nervous system based theory of development appear not to answer some basic questions, while militating against the investigation of alternative propositions. A few of these other hypotheses have been suggested. Although no experimentum crucis is apparent in so complex a preparation as the rapidly growing and differentiating rat pup, the suggestion that age-related activity changes result from an altered intralitter ecology is more subject to empirical validation (and disproof) than the more vague analogy between this behavioral ontogenesis and the developing hippocampus.

\section{REFERENCES}

Altman, J., \& Das, G. D. Autoradiographic and histological evidence of postnatal hippocampal neurogenesis in rats. Journal of Comparative Neurology, 1965, 124, 319-336.

Blanck, A.. Hard, E., \& Larsson, K. Ontogenetic development of orienting behavior in the rat. Journal of Comparative \& Physiological Psychology, 1967, 63, 327-328.

Bolles, $R$. C, Grooming behavior in the rat. Journal of Comparative \& Physiological Psychology, 1960, 53, 306-310.

Bolles, R. C., \& Woods, P. J. The ontogeny of behavior in the albino rat. Animal Behaviour, 1964, 12, 427-441.

Bronstein, P. M. Open-field behavior of the rat as a function of age: Cross-sectional and longitudinal investigations. Journal of Comparative \& Physiological Psychology, 1972, 80, 335-341.

Campbell, B. A., Lytle, L. D., \& Fibiger, H. C. Ontogeny of adrenergic arousal and cholinergic inhibitory mechanisms in the rat. Science, $1969,166,637-638$.

Carlton, P. L. Cholinergic mechanisms in the control of behavior by the brain. Psychological Review, 1963, 70, 19-39.

Carlton, P. L. Brain acetyl-choline and inhibition. In J. T. Tapp (Ed.), Reinforcement and behavior. New York: Academic Press, 1969. Pp. 286-327.
Dember, W. N. Alternation behavior. In D. W. Fiske and S. R. Maddi (Eds.), Functions of varied experience. Homewood, Ill: Dorsey, 1961. Pp. 227-252.

Douglas, R. J. Pavlovian conditioning and the brain. In R. A. Boakes and M. S. Halliday (Eds.), Inhibition and learning. New York: Academic Press, 1972. Pp. 529-553.

Douglas, R. J., Peterson, J. J., \& Douglas, D. P. The ontogeny of a hippocampusdependent response in two rodent species. Behavioral Biology, 1973, 8, 27-38.

Eibl-Eibesfeldt, I. Ethology: The biology of behavior. New York: Holt, Rinehart, \& Winston, 1970.

Feigley, D. A., Parsons, P. A., Hamilton, L. W., \& Spear, N. E. Development of habituation to novel environments in the rat. Journal of Comparative \& Physiological Psychology, 1972, 79 , 443-452.

Galef, B. G., Jr., \& Clark, M. M. Mother's milk and adult presence: Two factors determining initial dietary selection by weanling rats. Journal of Comparative \& Physiological Psychology, 1972, 78, 220-225.

Harper, L. V. Ontogenetic and phylogenetic functions of the parent-off spring relationship in mammals. In D. S. Lehrman,
R. A. Hinde, and E. Shaw (Eds.), Advances in the study of behavior. Vol. 3. New York: Academic Press, 1970. Pp. 75-117.

Krecek, J. The theory of critical developmental periods and postnatal development of endocrine functions. In $E$. Tobach, L. R. Aronson, and E. Shaw (Eds.), The biopsychology of development. New York: Academic Press, 1971. Pp. 233-249.

Martinek, Z., \& Lat, J. Ontogenetic differences in spontaneous reactions of dogs to new environment. Physiologia Bohemoslovaca, $1968,17,545-552$.

Riccio, D. C., \& Schulenburg, C. J. Age-related deficits in acquisition of a passive-avoidance response. Canadian Journal of Psychology, 1969, 23, 429-437.

Roberts, W. W., Dember, W. N., \& Brodwick, M. Alternation and exploration in rats with hippocampal lesions. Journal of Comparative \& Physiological Psychology, 1962, 55, 695-700.

Rosenblatt. J. S., \& Lehrman, D. S. Maternal behavior of the laboratory rat. In H. L. Rheingold (Ed.), Maternal behavior in mammals. New York: Wiley, 1963. Pp. 8-57.

Schulenburg, C. J., Riccio, D. C., \& Stikes, E. R. Acquisition and retention of a passive-avoidance response as a function of age in rats. Journal of Comparative \& Physiological Psychology, $1971,74,75-83$.

Tapp, J. T. Activity, reactivity, and the behavior-directing properties of stimuli. In J. T. Tapp (Ed.), Reinforcement and behavior. New York: Academic Press, 1969. Pp. 148-177.

Winer, B. J. Statistical principles in experimental design. New York: McGraw-Hill, 1962.

\section{NOTE}

1. Douglas and his colleagues showed a significant increase in the probability of spontaneous alternation in rats between the ages of 18 and 23 days. Both longitudinal and cross-sectional studies from our laboratory have replicated the Douglas et al (1973) finding and have shown further that 15-day-old rats, like Douglas's youngest Ss, display only chance levels of T-maze alternation.

(Received for publication A ugust 6, 1973; revision received November 9,1973 .) 